\title{
MEASUREMENT OF OCULAR BLOOD FLOW VELOCITY USING COLOUR DOPPLER IMAGING IN LOW TENSION GLAUCOMA
}

\author{
ZAHIDA BUTT ${ }^{1}$, GRAHAM McKILLOP ${ }^{2}$, COLM O'BRIEN $^{1}$, PAUL ALLAN $^{2}$ and \\ PETER ASPINALL ${ }^{1}$ \\ Edinburgh
}

\begin{abstract}
SUMMARY
The purpose of this study was to compare the velocity of blood flow and vascular resistance measured by colour Doppler imaging in the ophthalmic and central retinal arteries in 34 eyes of 34 patients (mean age 68.1 years) with low tension glaucoma (LTG) and 17 eyes of 17 agematched normal controls (mean age 65.2 years). The Acuson 128 machine (using a 7.5 MHz probe) was used to measure peak systolic velocity (PSV), end-diastolic velocity (EDV) and resistive index (RI). The EDV of the ophthalmic artery (OA) in the LTG was significantly ( $p$ $=0.04$ ) less than in the normal control group. There was a significant $(p=0.02)$ increase in the vascular RI of both the $\mathrm{OA}$ and central retinal artery in the LTG group compared with the normal controls. The OA RI increased with age $(r=0.61, p=0.0001)$, and the $\mathrm{OA}$ EDV decreased with age $(r=-0.50, p=0.003)$, in the LTG group but not in the normal control group. The results suggest an increased resistance to blood flow in the ophthalmic and central retinal arteries of LTG patients.
\end{abstract}

Low tension glaucoma (LTG) is characterised by glaucomatous optic disc cupping and visual field loss in eyes that have consistently normal $(<22 \mathrm{mmHg})$ intraocular pressures (IOP) in the absence of any intraocular or intraocular lesion. In the Beaver Dam Eye Study recently published by Klein et al. ${ }^{1}$ the overall prevalence of primary open angle glaucoma (POAG) was $2.1 \%$. This was only slightly higher than that recently reported for the Caucasian population participating in the Baltimore Eye Study. ${ }^{2}$ The estimated prevalence of LTG is approximately $15 \%$

From: ${ }^{1}$ Princess Alexandra Eye Pavilion and ${ }^{2}$ Radiology Department, Royal Infirmary of Edinburgh, Edinburgh, UK. Correspondence to: Dr Colm O'Brièn, FRCS, FRCOphth, Princess Alexandra Eye Pavilion, Royal Infirmary of Edinburgh, Chalmers Street, Edinburgh EH3 9HA, UK. Fax: 031-519-5405. of all POAG patients. ${ }^{3}$ Thus, 1 in 6 patients with POAG will have normal IOP.

The pathogenesis of LTG is still uncertain, but recently there has been an increased interest in a vascular aetiology. Reduced ocular perfusion and hence slow ongoing chronic ischaemia of the optic nerve head may give rise to a pale cupped disc. Evidence supporting a vascular mechanism can be found in the presence of optic disc haemorrhages, ${ }^{4-6}$ the findings of fluorescein angiography, ${ }^{7,8}$ analysis of haematological factors, ${ }^{9-11}$ pulsatile ocular blood flow measurements, ${ }^{12}$ digital blood flow measurements, ${ }^{13-17}$ the association with migraine ${ }^{18}$ and transcranial Doppler ultrasound measurements. ${ }^{19}$

The purpose of our study was to analyse the vascular component in LTG in greater detail by using a non-invasive method, colour Doppler imaging (CDI), to measure blood velocity and vascular resistance in the ophthalmic artery and central retinal artery in patients with LTG and in agematched normal healthy volunteers.

\section{PATIENTS}

Thirty-four LTG patients (mean age 68.1 years, SD 8.7) and 17 normal controls (mean age 65.2 years, SD 4.7) underwent CDI. This age difference between LTG and control patients was not statistically significant $(p=0.20)$. Regional ethics committee approval was obtained for this study and informed consent was obtained from all patients.

The inclusion criteria for the LTG patients were as follows:

1. Characteristic optic disc changes and visual field loss (Humphrey visual field analyser, programme 24-2) and IOP $<22 \mathrm{mmHg}$ as confirmed by diurnal inpatient phasing.

2. The exclusion of intracranial pathology that might 


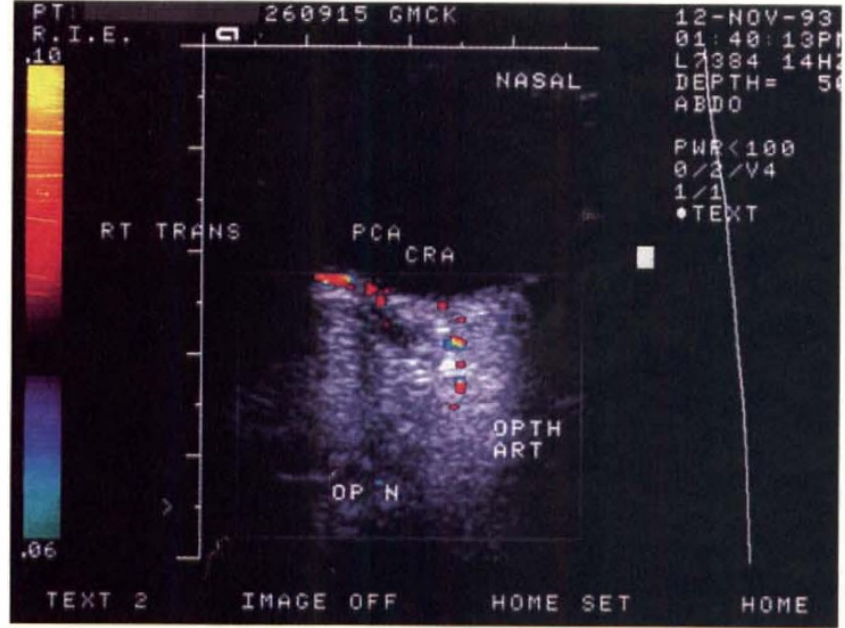

Fig. 1. Colour Doppler ultrasound showing flow in the ophthalmic artery and central retinal artery.

mimic the disc or visual field changes by plain skull radiographs and CAT scanning.

3 . Open angles on gonioscopy.

4. Visual acuity of $6 / 12$ or better.

5. No previous laser or surgical intervention.

6. No previous history of ocular inflammation.

Patients using topical glaucoma medications, systemic beta-blockers, calcium channel blockers or steroids were excluded. Those LTG patients who were using topical glaucoma medications $(n=17)$ had a wash-out period of 1 month prior to hospital admission for diurnal IOP phasing and CDI. Seventeen other LTG patients were recruited prospectively from the glaucoma new patient clinic and had inpatient phasing and CDI carried out prior to commencement of any glaucoma medication.

In the LTG group, 10 patients had a significant cardiovascular history (2 of whom were also diabetics). Two had a history of cerebrovascular accidents without long-term sequelae; 3 had previously suffered from transient ischaemic attacks; 2

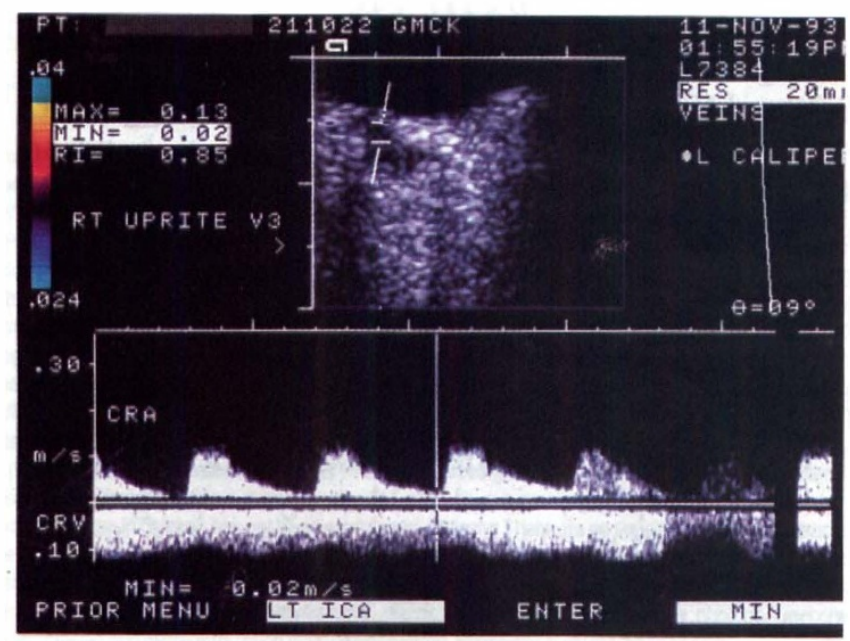

Fig. 3. Doppler frequency shift trace for the central retinal artery.

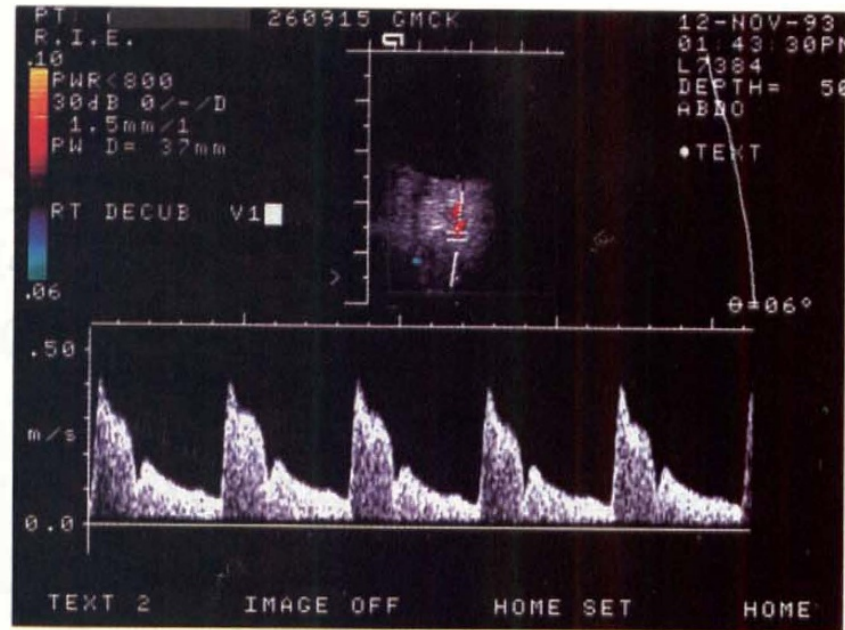

Fig. 2. Doppler frequency shift trace for the ophthalmic artery.

had chronic obstructive airways disease with emphysema and 1 had a history of deep venous thrombosis with pulmonary thrombo-embolism. Drug history revealed that 4 patients were on diuretics, 3 on nitrates, 3 on digoxin, 3 on aspirin, 2 on salbutamol inhalers (one of these patients was on Becloforte $(\mathrm{A} \& \mathrm{H})$ inhaler for acute respiratory attacks), and 1 on long-term warfarin. Five LTG patients had elevated diastolic blood pressure $(>95 \mathrm{mmHg}$ ) during their inpatient admission but were not on medications for this. Seven LTG patients had a previous history of migraine. On direct questioning 15 LTG patients were found to have a positive history of cold feet and hands (sometimes necessitating wearing socks in bed at night or gloves in summer). Six LTG patients were found to have a microcytic hypochromic anaemia on venepuncture, 2 of whom had significant blood loss after major abdominal surgery. Only 5 of the LTG patients were smokers.

The normal healthy volunteers were recruited from either the Women's Royal Voluntary Service at the hospital, from the hospital staff or were friends/relatives of the LTG patients. None of the control subjects had any significant cardiovascular, respiratory, neurological or ophthalmological history and they were not on any regular medication. One control subject was mildly hypertensive and did not require any treatment for this, while another was a mild diabetic who was diet-controlled with no problems. Seven control subjects had a history of migraine and 3 had a history of cold feet and hands. Only 1 normal volunteer was a smoker.

\section{METHODS}

During the hospital admission, CDI was performed at the Department of Radiology with an Acuson 128 machine (Mountain View, CA), with the patient supine, eyes closed and directing the gaze towards 
Table I. Mean (SD) blood flow velocity $(\mathrm{cm} / \mathrm{s})$ and resistance index

\begin{tabular}{lccc}
\hline & $\begin{array}{c}\text { Low tension } \\
\text { glaucoma } \\
(n=34)\end{array}$ & $\begin{array}{c}\text { Normal } \\
\text { controls } \\
(n=17)\end{array}$ & $\begin{array}{c}p \\
\text { value }\end{array}$ \\
\hline $\begin{array}{l}\text { Central retina artery } \\
\text { PSV }\end{array}$ & $12.8(9.1)$ & $13.4(6.3)$ & 0.79 \\
EDV & $1.9(1.9)$ & $2.6(1.6)$ & 0.23 \\
RI & $0.87(0.09)$ & $0.80(0.08)$ & 0.02 \\
Ophthalmic artery & & & \\
PSV & $30.4(7.6)$ & $30.1(9.9)$ & 0.89 \\
EDV & $6.6(2.9)$ & $8.4(2.9)$ & 0.04 \\
RI & $0.77(0.08)$ & $0.72(0.05)$ & 0.02 \\
\hline PSV, peak systolic velocity: EDV, end-diastolic velocity: RI, resistive \\
index.
\end{tabular}

the ceiling. Sterile coupling gel was applied to the eyelids and, using a $7.5 \mathrm{MHz}$ probe, the examination was carried out with avoidance of undue manual pressure on the probe according to the technique used by Baxter and colleagues. ${ }^{20,21}$ The colour Doppler window was localised over the retrobulbar area and flow in the ophthalmic artery (OA) and central retinal artery (CRA) identified (Fig. 1). A pulsed wave sample gate $(1.5 \mathrm{~mm} \times 1.5 \mathrm{~mm})$ was then positioned over the area of CDI flow and a Doppler frequency shift trace obtained (Figs. 2, 3). A trace was considered satisfactory if three consecutive waveforms were identified, allowing the mean values from three cardiac cycles to be obtained. Using a cross-hair caliper, peak systolic velocity (PSV) and end-diastolic velocity (EDV) were measured (in $\mathrm{cm} / \mathrm{s}$ ), and the resistive index (RI) derived from the formula:

$$
\mathrm{RI}=\frac{\mathrm{PSV}-\mathrm{EDV}}{\mathrm{PSV}}
$$

Angle correction was applied to the pulsed Doppler recordings where possible to minimise errors in the measured velocities. This is important as the velocities are derived from the Doppler frequency shift equation which is dependent on the cosine of the angle of interrogation. ${ }^{22}$ However, it is recognised that in these small retrobulbar vessels the angle correction may not be exact and may affect the velocity values obtained. This will not affect the RI value, though, as this is a ratio.

The CDI was performed by an experienced radiologist who was completely masked as to the identity of the patients. One eye of each LTG patient and control subject was used in the study. In the LTG group the eye with the greater glaucomatous damage was selected if both eyes had visual field loss, while one eye was chosen at random in the control group.

\section{Statistical Analysis}

An unpaired Student's $t$-test was used to analyse measurements for the PSV, EDV and RI values. Simple linear regression analysis was used to examine the association between the velocity measurements and age.
Table II. Correlation between age and blood flow velocity

\begin{tabular}{|c|c|c|c|c|}
\hline & \multicolumn{2}{|c|}{$\begin{array}{l}\text { Low tension } \\
\text { glaucoma } \\
\qquad(n=34)\end{array}$} & \multicolumn{2}{|c|}{$\begin{array}{l}\text { Normal controls } \\
\quad(n=17)\end{array}$} \\
\hline & $r$ & $p$ value & $r$ & $p$ value \\
\hline \multicolumn{5}{|c|}{ Ophthalmic artery } \\
\hline PSV & 0.20 & 0.26 & 0.03 & 0.90 \\
\hline EDV & -0.50 & 0.003 & 0.16 & 0.54 \\
\hline $\mathrm{RI}$ & 0.61 & 0.0001 & 0.17 & 0.50 \\
\hline \multicolumn{5}{|c|}{ Central retinal artery } \\
\hline PSV & 0.31 & 0.08 & 0.10 & 0.71 \\
\hline EDV & 0.27 & 0.11 & 0.06 & 0.81 \\
\hline RI & -0.18 & 0.32 & 0.02 & 0.94 \\
\hline
\end{tabular}

\section{RESULTS}

There was a statistically significant $(p=0.02)$ increase in the RI of both the OA and CRA in the LTG group compared with the controls (Table I). There was no significant difference demonstrated in the PSV of either vessel (Table I). The OA EDV in the LTG group was significantly less than that of the normal controls ( $p=0.04$; Table I).

A positive correlation was noted between OA RI and age $(r=0.61, p=0.0001)$, and a negative correlation between OA EDV and age $(r=-0.50$, $p=0.003)$ in the LTG group but not in the control group (Table II). No such correlation was noted between the CRA velocity indices and age in either the LTG or normal control groups (Table II).

\section{DISCUSSION}

The technique of CDI was initially described in 1979 by Eyer et $a l^{23}$ and used widely in cardiology investigations, peripheral vascular disease and, more recently, in investigations of other systems. ${ }^{24}$ Investigation of disorders of the orbit was first reported in 1989 by Erickson et al. ${ }^{25}$ Direct studies of the ocular circulation in humans remains difficult. CDI facilitates the examination of blood velocity in sites of complex vasculature by providing simultaneous Doppler and B-scan ultrasound images on a monitor. It allows for the non-invasive examination of blood flow velocity in the OA, CRA and posterior ciliary arteries. ${ }^{25-33}$

Our data show a significantly greater vascular RI in the OA and CRA of the LTG group compared with age-matched normal controls. The RI ratio can be increased either by an increase in PSV and/or a decrease in EDV. The EDV for both the OA and CRA in the LTG group was lower than in the normal control group although this velocity index was only reduced significantly $(p=0.04)$ in the OA. The PSV was not significantly different between the groups in either artery. Thus it appears that in this study the major contribution to the increased vascular resistance was the reduced end-diastolic blood flow velocity.

In a simple theoretical model, the increase in RI 
could occur distal to a single, discrete stenosis. ${ }^{22}$ However, the situation is complex and speculative in these patients. If atherosclerosis is the postulated pathogenesis, then there may be more than one stenosis and these stenoses may be of varying severity and position. Hence it is possible to infer that as a raised RI was found in this study of LTG patients there is presumably a stenosis somewhere in the ophthalmic and central retinal arteries. However, it is not possible to state the exact site or severity. It is not clear whether this reduced velocity and raised resistance in these vessels results in the features of pathological cupping and pallor of the optic disc in LTG. These vascular changes may arise secondary to loss of neural elements in the retina. This is, however, unlikely to produce a stenosis or narrowing in either the OA or CRA, which is the most likely cause of the elevated vascular resistance observed in this study.

Blood velocity is not equivalent to volume blood flow, which requires knowledge of the diameter of vessels for its calculation. It is not possible to measure volume blood flow with this technique because of the difficulty in measuring the diameter of these blood vessels accurately.

A large percentage $(71 \%)$ of the LTG patients were found to have arterial disease and a significant number $(65 \%)$ had a history of vasospastic disorder associated with Raynaud's phenomenon and/or migraine. This may account for the compromised blood flow velocity observed in this group of patients. Patients taking systemic calcium channel blockers and beta-blockers were excluded from the study because of their effects on vascular calibre and therefore flow velocity. If patients taking these medications were included in the study, the percentage of patients with arterial disease would be even higher and the blood velocity further compromised.

A significant positive correlation was noted between OA RI and age such that vascular resistance increased with age in the LTG group but not in the control group (Table II). This probably reflects the large number of LTG patients with arterial disease, the effects of which will increase with age. A significant negative correlation was noted between OA EDV and age in the LTG group but not in the normal controls, such that with increasing age there was a reduction in the EDV (Table II). These age-related results are comparable to those found by Drance's group using transcranial Doppler ultrasound in normal controls and glaucomatous patients $^{19,34}$ and also to reports by Michelson ${ }^{35}$ and Guthoff $e t a l .{ }^{36}$ using CDI on normal patients. The technique of transcranial Doppler ultrasound is possibly not as accurate as CDI as there is no direct visualisation of the vessels, which is a potential source of error.

Hayreh $^{37}$ has shown that the major source of blood supply to the optic nerve head comes from the posterior ciliary circulation. Therefore, CDI of the posterior ciliary arteries (PCA) would provide the best evidence of vascular compromise of the optic nerve head in glaucoma. However, the technique has limitations for imaging this particular area of the vasculature. Firstly, it is not obvious whether the vessel imaged is either the long or the short PCA. Secondly, by using a Doppler sample gate of $1.5 \mathrm{~mm}$ $\times 1.5 \mathrm{~mm}$, more than one PCA may be analysed at any particular time. This may lead to uncertainty as to whether the same PCA is being imaged in each patient examined. In addition, there are multiple PCAs in each patient and their number and position are variable. In theory, the PCAs should all be analysed separately. Hence, analysis of the PCA indices was excluded from the study. Further refinements in the technique of CDI may, in the future, provide quantitative data on blood flow in the PCA.

Drance and Schulzer ${ }^{38}$ have presented biostatistical evidence which suggests that there are two subgroups of glaucoma patients, whereby glaucoma is not only an IOP-related disease but also a vascular disease. CDI may provide a means of measuring part of the vascular component in glaucoma in greater detail. It would be especially helpful to separate the IOP-related glaucoma patients from the vascular glaucoma patients as this would have therapeutic implications. In the long term, CDI may play a role in glaucoma management by establishing whether treatment has a beneficial effect on the blood supply of the optic nerve.

This research was supported by a grant from the Guide Dogs for the Blind Association. The authors have no proprietary interest in the equipment used in this study.

Key words: Central retinal artery, Colour Doppler imaging, Glaucoma, Ophthalmic artery.

\section{REFERENCES}

1. Klein BE, Klein R, Sponsel WE, et al. Prevalence of glaucoma: the Beaver Dam Eye Study. Ophthalmology 1992;99:1499-504.

2. Tielsch JM, Katz J, Singh K, et al. A population based evaluation of glaucoma screening: the Baltimore Eye Survey. Am J Epidemiol 1991;134:1102-10.

3. Hitchings RA. Low tension glaucoma: its place in modern glaucoma practice. $\mathrm{Br} \mathrm{J}$ Ophthalmol 1992;76:494-6.

4. Drance SM, Begg IS. Sector haemorrhage: a probable acute ischaemic disc change in chronic simple glaucoma. Can J Ophthalmol 1970;5:137-41.

5. Drance SM, Fairclough M, Butler DM, Kottler MS. The importance of disc haemorrhage in the prognosis of chronic open angle glaucoma. Arch Ophthalmol 1977;95:226-8.

6. Suzanna R, Drance SM, Douglas GR. Disc haemorrhages in patients with elevated intraocular pressure: occurrence with and without field changes. Arch Ophthalmol 1979;97:284-5. 
7. Hitchings RA, Spaeth GL. Fluorescein angiography in chronic simple and low tension glaucoma. $\mathrm{Br} \mathrm{J}$ Ophthalmol 1977;61:126-3.

8. Hayreh SS, Walker WM. Fluorescent fundus photography in glaucoma. Br J Ophthalmol 1967;63:982-9.

9. Drance SM, Sweeney VP, Morgan RW, Feldman F. Studies of factors involved in the production of low tension glaucoma. Arch Ophthalmol 1973;89:457-65.

10. Klaver JHJ, Greve EL, Goslinga H, Geijssen HC, et al. Blood and plasma viscosity measurements in patients with glaucoma. Br J Ophthalmol 1985;69:765-70.

11. Mary A, Serre I, Brun J-F, Arnaud B, Bonne C. Erythrocyte deformability measurements in patients with glaucoma. J Glaucoma 1993;2:155-7.

12. James CB, Smith SE. Pulsatile ocular blood flow in patients with low tension glaucoma. $\mathrm{Br} \mathrm{J}$ Ophthalmol 1991;75:466-70.

13. Drance SM, Douglas GR, Wijsman K, Schulzer M, Britton RJ. Response of blood flow to warm and cold in normal and low tension glaucoma patients. Am J Ophthalmol 1988;105:35-9.

14. Flammer J, Guthauser U, Mahler F. Do ocular vasospasms help cause low tension glaucoma? Doc Ophthalmol Proc Ser 1987;397:399.

15. Guthauser U, Flammer J, Mahler F. The relationship between digital and ocular vasospasm. Graefes Arch Clin Exp Ophthalmol 1988;226:224-6.

16. Gasser P, Flammer J. Blood cell velocity in the nailfold capillaries of patients with normal tension and high tension glaucoma. Am J Ophthalmol 1991;111:585-8.

17. Gasser PJ, Flammer J, Guthauser U, Niesel P, Mahler F, Linder HR. Bedeutung des vasospastischen Syndrom in der Augenheilkunde. Klin Monatsbl Augenheilkd 1986;188:398-9.

18. Ederer F. Migraine and low tension glaucoma. Invest Ophthalmol Vis Sci 1986;27:632-3.

19. Rojanapongpun P, Drance SM, Morrison BJ. Ophthalmic artery flow velocity in glaucomatous and normal subjects. Br J Ophthalmol 1993;77:25-9.

20. Baxter GM, Williamson TH, McKillop G, Dutton GN. Colour Doppler ultrasound of orbital and optic nerve blood flow: effects of posture and timolol $0.5 \%$. Invest Ophthalmol Vis Sci 1992;33:604-10.

21. Williamson TH, Baxter GM, Dutton GN. Colour Doppler velocimetry of the optic nerve head in arterial occlusion. Ophthalmology 1993;100:312-17.

22. Meire HB. Abdominal and general ultrasound, vol 1. Edinburgh: Churchill Livingstone, 1993: 65-95.

23. Eyer MK, Brandestini MA, Phillips DJ, Baker DW.
Colour digital echo/Doppler image presentation. Ultrasound Med Biol 1981;7:21-31.

24. Meritt CRB. Doppler colour flow imaging. J Clin Ultrasound 1987;15:591-7.

25. Erickson SJ, Hendrix LE, Massarro BM, Harris GJ, Lewandowski MF, Foley WD, Lawson TL. Colour Doppler flow imaging of the normal and abnormal orbit. Radiology 1989;173:511-6.

26. Aburn NS, Sergott RC. Orbital colour Doppler imaging. Eye 1993;7:639-47.

27. Mitchell DG, Golberg BB. Colour Doppler imaging of the eye and orbit. Arch Ophthalmol 1991;109:527-31.

28. Flaherty PM, Sergott RC, Lieb W, Bosley TM, Sarvino PJ. Optic nerve sheath decompression may improve blood flow in anterior ischaemic optic neuropathy. Ophthalmology 1993;200:297-305.

29. Canning CR, Restori M. Doppler ultrasound studies of the ophthalmic artery. Eye 1988;2:92-5.

30. Guthoff RF, Berger RW, Winkler P, Helmke K, Chumbley LC. Doppler ultrasonograph of the ophthalmic and central retinal vessels. Arch Ophthalmol 1991;109:532-6.

31. Lieb WE, Flaharty PM, Ho A, Sergott R. Colour Doppler imaging of the eye and orbit: a synopsis of a 400 case experience. Arch Ophthalmol 1992;204:50-5.

32. Regills CD, Sergott RC, Ho A, Belmont JB, Fischer DH. Hemodynamic alterations in the acute retinal necrosis syndrome. Ophthalmology 1993;100:1171-6.

33. Ho AC, Lieb WE, Flaherty PM, Sergott RC, Brown GC, Bosley TM, Savino PJ. Colour Doppler imaging of the ocular ischaemic syndrome. Ophthalmology 1992; 99:1453-62.

34. Rojanapongpun P, Drance SM. Velocity of ophthalmic arterial flow recorded by Doppler ultrasound in normal subjects. Am J Ophthalmol 1993;115:174-80.

35. Michelson G, Grierth $\mathrm{K}$, Prjem R, Laumer R. Blutflussgeschwindigkeit in der A. ophthalmica durch transbulbere Dopplersonographie. Fortschr Ophthalmol 1989;86:331.

36. Guthoff RF, Berger RW, Winkler P, Helmke K, Chumbley LC. Doppler ultrasonography of malignant melanomas of the uvea. Arch Ophthalmol 1991;109: 537-41.

37. Hayreh SS. Blood supply of the optic nerve head and its role in optic atrophy, glaucoma and oedema of the optic disc. Br J Ophthalmol 1969;53:721-48.

38. Drance SM, Schulzer M. Biostatistical evidence for two distinct chronic open angle glaucoma populations. $\mathrm{Br} \mathrm{J}$ Ophthalmol 1990;74:196-200. 